\title{
Respiratory failure and mechanical ventilation in severe bronchiolitis
}

\author{
M H LEBEL, M GAUTHIER, J LACROIX, E ROUSSEAU, AND M BUITHIEU \\ Paediatric Intensive Care Unit, Hôpital Sainte-Justine, University of Montreal, Canada
}

SUMMARY A retrospective review of children who needed mechanical ventilation for severe bronchiolitis identified 62 cases over a 10 year period. The mean age at initiation of ventilation was 73 days (range: 14-201). Compared with a group of 150 children in hospital for bronchiolitis but not transferred to the intensive care unit, these 62 cases were significantly younger $(73 \cdot 0$ compared with 166.3 days), and smaller ( 4.5 compared with $6.8 \mathrm{~kg}$ ), and significantly more had been born prematurely ( $40 \%$ compared with $16 \%)$. Taken independently, age, weight, and prematurity were significantly associated with the need for artificial ventilation, weight being the most important factor. Using stepwise logistic regression, prematurity in itself added to the quality of the prediction but age did not. The mean duration of mechanical ventilation was 105 hours (range 2-381). Duration of ventilation was significantly longer in children with a low gestational age at birth and a positive familial history of atopy. There were no deaths, and no patient developed pneumothorax or pneumomediastinum. Mechanical ventilation is well tolerated and safe in acute bronchiolitis.

Viral bronchiolitis is one of the most common paediatric respiratory diseases and an important cause of admission to paediatric wards. Every child has a $1 \%$ to $2 \%$ risk of being admitted to hospital with bronchiolitis in the first year of life ${ }^{1} ; 5 \%$ of those will have acute respiratory failure ${ }^{2}$ and about $1 \%$ will die. ${ }^{13}$ It is 20 years since the first patients were treated with artificial ventilation, ${ }^{245}$ but despite its widespread use, particularly for severe cases, there have been only a few recent reports on the subject and they have focused mainly on the technical aspects of mechanical ventilation.

The purposes of this review were to trace the evolution of the illness in children needing mechanical ventilation for a first episode of viral bronchiolitis and to find out their demographic characteristics. In the second part of the study, we compared the demographic data of the ventilated group with those of a control group consisting of patients admitted to hospital but not to the intensive care unit to evaluate the importance of factors such as age, prematurity, and weight as prognostic factors for the need for ventilation.

\section{Patients and methods}

The medical records of all patients who were admitted for treatment of bronchiolitis to the 24 bed paediatric intensive care unit of the Sainte-Justine Hospital in Montreal during the 10 year period 1 January 1976 to 31 December 1985 were retrospectively reviewed. Chart numbers were identified from the records of discharge diagnoses kept in the paediatric intensive care unit. Children with underlying cardiopulmonary abnormalities, serious congenital malformations, and immunodeficiency diseases were excluded, as it is difficult to assess retrospectively the relative effect of these factors on the course of severe bronchiolitis. Children who had had previous episodes of bronchiolitis were also excluded, as well as those not meeting the diagnostic criteria used in the present study.

CRITERIA FOR ENTRY INTO THE STUDY

The diagnostic criteria of bronchiolitis included tachypnoea, cough, chest retractions, prolonged expiratory time, pulmonary rales, and hyperinflation of the lungs on chest radiographs. Criteria for admission to the paediatric intensive care unit included at least one of the following signs: exhaustion caused by expiratory obstruction, greatly diminished air entry, cyanosis of lips and mucous membranes when breathing room air, respiratory pauses or apnoea, or both, and respiratory or meta- 


\section{Lebel, Gauthier, Lacroix, Rousseau, and Buithieu}

bolic acidosis. The diagnosis of respiratory insufficiency was based on both clinical and biochemical data including alteration of mental state, cyanosis when fractional inspiratory oxygen $\left(\mathrm{FiO}_{2}\right)$ was $0 \cdot 4$, frequent or prolonged episodes of apnoea, a rapid increase in carbon dioxide tension $\left(\mathrm{PaCO}_{2}\right), \mathrm{PaCO}_{2}$ greater than $10 \mathrm{kPa}$, or an oxygen tension $\left(\mathrm{PaO}_{2}\right)$ less than $7 \mathrm{kPa}$ when $\mathrm{FiO}_{2}$ was $1 \cdot 0$. A nosocomial infection was considered likely if the child was in hospital for a problem not associated with the respiratory system and developed wheezing seven days or more after the admission. Nosocomial infection was also considered when a child had been discharged and was readmitted with wheezing that developed less than three days after the initial discharge from the hospital. We defined prematurity as birth before 38 weeks' gestation, and a family history of atopy if the parents or siblings of the patient, or both, had a history of asthma, eczema, urticaria, or allergic rhinitis. It was assumed that if a finding (such as history of atopy) was not recorded in the chart, it was not present.

\section{MANAGEMENT}

All patients with acute respiratory insufficiency were ventilated with intermittent mandatory positive pressure ventilation by a volumetric (Bourns) or a time cycled (Sechrist) ventilator. Initial ventilatory settings were as follows: a peak inspiratory pressure of 25 to $35 \mathrm{~cm} \mathrm{H}_{2} \mathrm{O}$ - enough to achieve adequate chest expansion; a ventilatory rate of 25 to 30 /minute; an inspiratory: expiratory ratio of $1: 2$ or longer; and a fraction of inspired oxygen of 0.5 to $0 \cdot 7$. Ventilatory settings were adjusted to keep the $\mathrm{pH}$ higher than $7 \cdot 35, \mathrm{PaO}_{2}$ greater than $10 \mathrm{kPa}$ and $\mathrm{PaCO}_{2}$ less than $7 \mathrm{kPa}$. If hypercarbia worsened, and retractions and respiratory rate increased, delivered tidal volume was increased by raising the ventilatory rate to $35 /$ minute, or the peak inspiratory pressure by increments of 3 to $5 \mathrm{~cm} \mathrm{H}_{2} \mathrm{O}$ to a maximum of $40-45 \mathrm{~cm} \mathrm{H}_{2} \mathrm{O}$. As the patient was improving the ventilation rate was progressively decreased until the patient was breathing spontaneously with a continuous positive airway pressure of 2 to $3 \mathrm{~cm} \mathrm{H}_{2} \mathrm{O}$. If the patient's condition remained stable for 4-12 hours on continuous positive airway pressure the patient was extubated and given oxygen with an oxygen hood. The duration of ventilation was defined as the total number of hours that the patient received positive pressure ventilation. All patients received intravenous hydration at maintenance rate $(80-90 \mathrm{ml} / \mathrm{kg} /$ day $)$ for some days. Sedative drugs (diazepam, morphine, or pethidine), muscular paralysis, theophylline derivatives, and antibiotics were used only when indicated. Patients given one dose or more of these agents were con- sidered to have received the drug. No patients were given diuretics or ribavirin.

\section{LABORATORY INVESTIGATIONS}

The initial investigations on admission to the intensive care unit included a complete blood count and a chest radiograph. Arterial blood gases were measured regularly before intubation, during mechanical ventilation, and as long as the pulmonary condition was thought to be unstable. Microbiological cultures were taken from the endotracheal site at the time of intubation, regularly twice a week as long as the patient remained intubated and more often if infection was suspected. Blood was cultured if bacteraemia was suspected. Viral cultures of throat, stools, and tracheal secretions, and viral serology (paired samples for serum for neutralising antibodies for respiratory syncytial virus, influenza, parainfluenza, and adenovirus) were routinely done only during the last three years of the period reviewed. Washes of endotracheal secretions were inoculated onto HEp2 cell lines especially sensitive for respiratory syncytial virus and onto cynomolgus monkey kidney, and human foreskin fibroblast cell lines, for the detection of other viruses. Pulmonary superinfection was diagnosed if persistent fever and leucocytosis (white cello count $\left.>15.0 \times 10^{9} / 1\right)$ were associated with purulent tracheal secretions and signs of pulmonary infiltra tion on chest radiographs. No pulmonary function tests were done.

\section{CONTROL PATIENTS}

To characterise patients requiring assisted ventilation more clearly, we analysed data from a control group of children with bronchiolitis who were admitted to hospital but not transferred to the intensive care unit. This group comprised infants and children who did not have underlying cardiopulmonary abnormalities, serious congenital malformations, or immunodeficiency diseases, and who were in hospital for the first time with bronchiolitis. Fifteen patients were chosen randomly (one of every five patients admitted was selected) by the medical records department for each of the 10 years of the study among all children admitted to our institution with this diagnosis; they were not matched with the ventilated group for age, sex, race, or month of admission.

\section{STATISTICAL ANALYSIS}

To compare clinical characteristics between ventilated and non-ventilated children, data were analysed by Student's $t$ test, $\chi^{2}$ with Yates's correction, and Fisher's exact test as appropriate. To determine the associations between duration of 
mechanical ventilation and age at admission, gestational age at birth, and $\mathrm{PaCO}_{2}$ before intubation, we calculated Pearson correlation coefficients by simple linear regression analysis. To determine the associations between duration of ventilation and familial history of atopy, infiltration on initial chest radiograph, new lung infiltrations during ventilation, and use of sedatives, the two tailed Mann-Whitney U test was used because the data were not normally distributed. Only p values of 0.05 or less were regarded as significant. The Bonferroni correction was used to account for multiple testing at a p value of $\leqslant 0 \cdot 005$. Stepwise logistic regression analysis was used to examine the relative contribution of the three following variables to the need of artificial ventilation: weight, age, and prematurity. ${ }^{9}$ The figures are given as mean (SD).

\section{Results}

Eighty one patients required assisted ventilation for severe bronchiolitis during the 10 year period reviewed. Nineteen children were excluded because of underlying pulmonary disease $(n=8)$, congenital heart disease $(n=3)$, multiple congenital malformations $(n=2)$, and previous episodes of bronchiolitis $(n=6)$. Sixty two patients were therefore included in the review. The male:female ratio was 1.3:1 (table 1) and the racial distribution was 53 white, eight black, and one Eskimo. The mean age at initiation of assisted ventilation was 73 days (range 14-201). Twenty five (40\%) were born prematurely. Only four had had neonatal respiratory distress syndrome and three of these required mechanical ventilation at birth; two had had transient tachypnoea of the newborn. Twelve (19\%) were thought to have acquired a nosocomial respiratory infection.

Among the comparative group of 150 children treated on general wards, the male:female ratio was $2 \cdot 1: 1$. The racial distribution consisted of 137 white, 12 black, and one Eskimo. These patients were significantly larger and older compared with the ventilated group (table 1) and the proportion of very young children (less than 2 months of age) significantly smaller (19\% compared with $48 \%$, $\mathrm{p}<0.0001)$. Prematurity was also encountered more often in the ventilated group, although the prevalence of respiratory distress syndrome and mechanical ventilation during the neonatal period was the same for both groups (table 1).

Stepwise logistic regression analysis was used to determine the relative effects of weight, age, and prematurity on the need for mechanical ventilation in the course of bronchiolitis. Taken independently each of these three factors was significantly related to the need for ventilation $(\mathrm{p}<0.001)$; weight, however, was the most significant factor determining the need for artificial ventilation. When weight was entered as the first step of the analysis (table 2), prematurity was associated with the need for mechanical ventilation, but age was not. When weight and prematurity were analysed together (second step of the analysis), age was not retained as a significant variable.

In the ventilated group the mean duration of symptoms of upper respiratory tract infection was 1.5 days before the onset of dyspnoea, and four days

Table 1 Clinical data of ventilated and non-ventilated children with bronchiolitis

\begin{tabular}{|c|c|c|c|c|c|}
\hline & $\begin{array}{l}\text { Ventilated group } \\
(n=62)\end{array}$ & $\begin{array}{l}\text { Control group } \\
(n=150)\end{array}$ & $\begin{array}{l}\text { Statistical } \\
\text { test }\end{array}$ & $\begin{array}{l}p \\
\text { Value }\end{array}$ & $\begin{array}{l}\text { Relative risk } \\
(95 \% \\
\text { confidence } \\
\text { interval) }\end{array}$ \\
\hline \multicolumn{6}{|l|}{ Age on admission (days): } \\
\hline Mean (SD) & $73.0(41.4)$ & $166 \cdot 3(139 \cdot 7)$ & \multirow[t]{2}{*}{ Mann-Whitney U } & \multirow[t]{2}{*}{$<0.001$} & \\
\hline Median (range) & $62(14-215)$ & $133(16-988)$ & & & \\
\hline Mean (SD) & $4 \cdot 5(1 \cdot 2)$ & $6 \cdot 8(2 \cdot 2)$ & \multirow[t]{2}{*}{ Mann-Whitney U } & \multirow[t]{2}{*}{$<0 \cdot 001$} & \\
\hline Median (range) & $4 \cdot 2(2 \cdot 5-7 \cdot 8)$ & $6 \cdot 6(2 \cdot 8-16 \cdot 7)$ & & & \\
\hline \multicolumn{6}{|l|}{ Gestation (weeks): } \\
\hline No $(\%)<32$ & $9(14)$ & 4 (3) & $\chi^{2}$ & $<0.001$ & $6.2(1.9$ to $20 \cdot 1)$ \\
\hline No $(\%) 32-37$ & $16(26)$ & $20(13)$ & $\chi^{2}$ & 0.046 & $2 \cdot 3(1.0$ to $5 \cdot 1)$ \\
\hline No $(\%) \geqslant 38$ & $37(60)$ & $126(84)$ & $\chi^{2}$ & $<0.001$ & $0.3(0.4$ to 0.6$)$ \\
\hline \multicolumn{6}{|l|}{ Sex: } \\
\hline Male:female & $35: 27$ & $102: 48$ & $\chi^{2}$ & $0 \cdot 11$ & \\
\hline distress syndrome & 4 (7) & $5 \quad(3)$ & Fisher's exact & $0 \cdot 21$ & \\
\hline \multicolumn{6}{|l|}{ No $(\%)$ who had mechanical } \\
\hline ventilation during neonatal period & $3(5)$ & 3 (2) & Fisher's exact & $0 \cdot 15$ & \\
\hline No $(\%)$ with family history of atopy & 12 (19) & 49 (33) & $\chi^{2}$ & $>0.05$ & \\
\hline
\end{tabular}


Table 2 Stepwise logistic regression analysis to examine the relative contribution of weight, age, and prematurity to the need for mechanical ventilation

\begin{tabular}{|c|c|c|c|c|c|c|}
\hline & \multirow[t]{2}{*}{ Coefficient } & \multirow[t]{2}{*}{ Standard error } & \multirow{2}{*}{$\begin{array}{l}\text { Coefficient/standard } \\
\text { error }\end{array}$} & $F$ value & \multirow[t]{2}{*}{$d f$} & \multirow[t]{2}{*}{ p Value } \\
\hline & & & & To enter/to remove & & \\
\hline \multicolumn{7}{|l|}{ Step 1: } \\
\hline Weight & $-0 \cdot 801$ & $0 \cdot 141$ & $-5 \cdot 664$ & -133.99 & 1,189 & $0 \cdot 017$ \\
\hline Prematurity & - & - & - & $5 \cdot 75 /-$ & 1,189 & $<0.0001$ \\
\hline Age & - & - & - & $0 \cdot 14 /-$ & 1,189 & 0.7128 \\
\hline Constant & $3 \cdot 4673$ & $0 \cdot 717$ & $4 \cdot 834$ & $-124 \cdot 76$ & 1,189 & $<0 \cdot 0001$ \\
\hline \multicolumn{7}{|l|}{ Step 2: } \\
\hline Weight & -0.761 & $0 \cdot 143$ & $-5 \cdot 317$ & $-/ 29.03$ & 1,188 & $<0.0001$ \\
\hline Prematurity & 0.458 & $0 \cdot 201$ & $2 \cdot 274$ & $-15 \cdot 31$ & 1,188 & 0.022 \\
\hline Age & - & - & - & $1 \cdot 26 /-$ & 1,188 & $0 \cdot 263$ \\
\hline Constant & 3.4763 & 0.732 & $4 \cdot 747$ & $-/ 23.14$ & 1,188 & $<0.0001$ \\
\hline
\end{tabular}

before mechanical ventilation was needed. Among initial laboratory studies, the mean haemoglobin concentration was $113(2 \cdot 5) \mathrm{g} / \mathrm{l}$ (range 74-180). The mean peripheral leucocyte count was $10 \cdot 8$ $(2 \cdot 6) \times 10^{9} / 1$ (range 4.9-21.0). Arterial blood gases were analysed in $56(90 \%)$ patients just before intubation; the mean $\mathrm{pH}$ was $7.20(0.10)$ range $6 \cdot 90-7 \cdot 36, \mathrm{PaCO}_{2}$ was $9 \cdot 6(2 \cdot 0) \mathrm{kPa}$, range 6.4-16.0, and mean bicarbonate was $27.4(4.4) \mathrm{mmol} / \mathrm{l}$, range $14 \cdot 2-35 \cdot 4$. It should be noted that many children deteriorated suddenly and unexpectedly, which could explain why some infants had acceptable acidbase values before ventilation as measurements were made when the clinical condition seemed to be stable. In six cases $(10 \%)$ the condition worsened so fast that the child had to be intubated immediately without time to sample blood gases. The initial chest radiographs showed at least one infiltrate in $\mathbf{3 8}$ of $\mathbf{6 2}$ patients $(61 \%)$, and $21(34 \%)$ had hyperinflation alone with or without increased bronchial markings.

Fifty patients were ventilated with Bourns ventilators and 12 with Sechrists. Duration of ventilation was 105 (79) hours, range 2-381, median 86. Seventeen patients $(27 \%)$ were ventilated for 48 hours or less, and $19(31 \%)$ between 49 and 96 hours.

There were no significant correlations between duration of mechanical ventilaton and age at admission $(r=0.0 ; p=0.782), \mathrm{PaCO}_{2}$ before intubation $(r=0 \cdot 1 ; p=0 \cdot 615)$, or the presence of infiltration on the initial chest radiograph (table 3 ). Low gestational age at birth correlated significantly with duration of ventilation $(r=0.3 ; p=0.017)$. Three other factors also correlated with the length of ventilation: positive family history of atopy, appearance of new infiltrates during ventilation, and the use of sedative (table 3).

Most children tolerated the mechanical ventila-
Table 3 Potential prognostic factors associated with duration of mechanical ventilation in 62 infants

\begin{tabular}{|c|c|c|}
\hline & $\begin{array}{l}\text { Mean (SD) duration } \\
\text { of mechanical } \\
\text { ventilation (hours) }\end{array}$ & $\begin{array}{l}p^{*} \\
\text { Value }\end{array}$ \\
\hline $\begin{array}{l}\text { Family history of atop } \\
\text { Yes }(n=12) \\
\text { No }(n=50)\end{array}$ & $\begin{array}{r}154 \cdot 7(85 \cdot 3) \\
93.6(73.4)\end{array}$ & 0.006 \\
\hline $\begin{array}{l}\text { Infiltration seen on fir } \\
\text { radiograph: } \\
\text { Yes }(n=38) \\
\text { No }(n=24)\end{array}$ & $\begin{array}{r}93 \cdot 3(62 \cdot 1) \\
124 \cdot 5(98 \cdot 6)\end{array}$ & $>0.05$ \\
\hline $\begin{array}{l}\text { Occurrence of new lur } \\
\text { infiltration during ve } \\
\text { Yes }(n=22) \\
\text { No }(n=40)\end{array}$ & $\begin{array}{r}139 \cdot 2(75 \cdot 8) \\
86 \cdot 8(75 \cdot 2)\end{array}$ & 0.002 \\
\hline $\begin{array}{l}\text { Sedation: } \\
\text { Used }(n=17) \\
\text { Not used }(n=45)\end{array}$ & $\begin{array}{r}127 \cdot 4(60 \cdot 3) \\
97 \cdot 1(84 \cdot 1)\end{array}$ & 0.02 \\
\hline
\end{tabular}

*Two failed Mann-Whitney U test.

tion well; sedation was used in only 17 of $62(27 \%)$ and muscular paralysis in two of $62(3 \%)$. Theophylline or its derivatives were given in six of $62(10 \%)$ of cases. Antibiotics were given to 56 of 62 of the patients $(90 \%)$, mainly because of an infiltrate on the chest radiograph. Microbiological cultures from blood, cerebrospinal fluid, and urine done during the period of ventilation were sterile. Tracheal secretions yielded one or more potential pathogens in 14 patients. We believe that in several cases these positive tracheal cultures represented colonisation rather than true infection; there was evidence of pulmonary superinfection in seven of $62(11 \%)$.

Viral cultures and serology were done in 43 and 25 ventilated patients, respectively. Respiratory syn- 
cytial virus was isolated by culture of tracheal or nasopharyngeal secretions in 12 patients, influenza $A$ and adenovirus in one each. A fourfold or greater rise in antibody titres to respiratory syncytial virus occurred in 10 patients, and for parainfluenza 3 titres in one.

Complications were uncommon. There were no deaths and no patient developed pneumothorax or pneumomediastinum. New infiltrations were seen on chest radiographs in a third of intubated patients. In most cases they were not accompanied by fever, leucocytosis, or purulent tracheal secretions, and were considered to be of mechanical rather than infectious origin. Length of stay in the hospital after assisted ventilation had been stopped was 12.4 $(12 \cdot 4)$ days, range 3-80.

\section{Discussion}

Young age is often mentioned as a marker of severity in acute bronchiolitis. ${ }^{1011}$ The higher mortality in younger patients ${ }^{11}$ can at least in part be associated with a higher rate of congenital malformations or of associated cardiopulmonary problems in this age group. Patients with these underlying conditions were not included in this review, so our results objectively confirm previous data showing that younger age is in itself a significant prognostic factor for acute respiratory failure in bronchiolitis. ${ }^{11}$ Heycock and Noble attributed this phenomenon to the comparatively greater degree of obstruction produced by exudate or mucosal oedema in small calibre bronchi ${ }^{11}$; this is surely the principal explanation for the association between young age and severity of bronchiolitis. Our data offer objective support for this hypothesis: using a stepwise logistic regression analysis, we found that weight was the most significant factor determining the need to be mechanically ventilated. We believe that young infants are at higher risk of developing respiratory insufficiency during an episode of acute bronchiolitis, mostly because they are smaller and thus have smaller airways. Only a prospective study, however, can assess the importance of each risk factor.

Prematurity has recently been mentioned as one of the conditions that seems to place a child at risk of severe or fatal respiratory syncytial virus infections. ${ }^{12}$ To date, however, only the likelihood of developing apnoea in the course of such an infection has been reported in infants who were born prematurely. ${ }^{13}{ }_{4}$ Our data show clearly that prematurity also predisposes to respiratory insufficiency secondary to acute bronchiolitis. Five of the seven children described by Joly et al $(71 \%),{ }^{4}$ six of 15 of the patients reported by Outwater and Crone
$(40 \%),{ }^{6}$ and 14 of 36 described by Floret and Gabai $(39 \%),{ }^{8}$ were also born prematurely; most of them had otherwise normal neonatal histories.

It is tempting to see a simple relation between the increased incidence of prematurity and the significantly lower mean weights in the ventilated compared with non-ventilated patients (table 1). Being smaller, infants who are born prematurely could be particularly at risk of developing severe bronchiolitis because of the smaller lumen of their bronchi, this explanation is possibly the most likely. None the less, the stepwise logistic regression analysis used to study the relative effects of weight, age, and prematurity showed that prematurity in itself adds to the quality of the prediction. Moreover, low gestational age was significantly correlated to the duration of mechanical ventilation.

Prematurely born children who do not have the respiratory distress syndrome have lower expiratory flow rates six to 12 years after birth than do children born at full term. ${ }^{15} 16$ Bertrand et al found an increased incidence of airway hyper-reactivity in babies born prematurely and their families. ${ }^{16}$ They suggested a possible association between the onset of premature birth and airway hyper-reactivity. This increased incidence of airway hyper-reactivity in prematurely born babies could predispose them to more severe bronchiolitis and acute respiratory failure. The duration of artificial ventilation was longer in those in our group of patients who had a family history of atopy, but the percentage of children with a family history of atopy was not significantly higher in the ventilated than in the nonventilated groups (table 1). At present we do not know enough to explain these observations satisfactorily. Immunological considerations must also be kept in mind. Infants born at full term are immunodeficient when compared with older children and adults in essentially all measurable immunological factors; preterm infants are further immunocompromised, making them more susceptible to life threatening infections, ${ }^{17}$ and possibly also to lower respiratory infections, as suggested by Ballow et al. ${ }^{18}$

Our review, as well as the reports of others, ${ }^{6-8}$ show that mechanical ventilation for children with bronchiolitis is a well tolerated procedure. Only $27 \%$ of our patients required sedation. We believe that the decision to use sedatives should be based on the patient's course, and that muscular paralysis should only be used to ensure adequate gas exchange.

Serious complications such as death, pneumothorax, or pneumomediastinum are unusual in patients who do not have underlying cardiopulmonary diseases or immunodeficiency. Such compli- 


\section{Lebel, Gauthier, Lacroix, Rousseau, and Buithieu}

cations did not occur in our series. Frankel et al described one case of pneumothorax and one case of acute pulmonary hypertension in 17 ventilated patients. ${ }^{7}$ In another series reporting 36 ventilated infants, two developed pneumothoraces and another had an unexplained cardiac arrest. ${ }^{8}$ Management of bronchiolitis in our intensive care unit has not changed appreciably over the period reviewed. Except for the use of ribavirin, principles of treatment have remained the same over the last 15 years. ${ }^{19}$

Except for low gestational age at birth and a family history of atopy, we were not able to identify other predictive factors for a long period of mechanical ventilation. There was an association between prolonged ventilation and the appearance of new lung infiltrates on chest radiographs. If most of these infiltrates had been associated with other clinical signs of infection we could speculate that bacterial pulmonary superinfection prolongs mechanical ventilation. This was not the case, however. Most of the new pulmonary densities were discovered on routine radiographs, and most were considered to be atelectasis. These infiltrates were probably a consequence of prolonged ventilation rather than a cause. Duration of ventilation was also longer in patients who received sedatives. These children were possibly the illest and the most difficult to ventilate, although this hypothesis is impossible to confirm retrospectively. We may also speculate that the use of sedation prolonged weaning from the ventilator, particularly in young children who are especially sensitive to the depressive effects of narcotics.

Bacterial infections do not seem to have a serious role in the course of acute bronchiolitis. ${ }^{20} \mathrm{~A}$ prospective randomised study has not shown any benefit from the use of antibiotics in children admitted to hospital with bronchiolitis. ${ }^{21}$ Nearly $90 \%$ of children in our ventilated group were given antibiotics. In most cases the antibiotics were prescribed for pulmonary infiltrates seen on the chest radiographs of critically ill, very young children. This attitude is understandable but one must realise that the bacterial infection rate is low.

Despite current recommendations, ${ }^{12}$ enthusiastic acceptance of ribavirin for treatment of respiratory syncytial virus infections must still be questioned. ${ }^{22} 23$ The efficacy of such treatment, especially in intubated patients, remains unproved. ${ }^{23} \mathrm{We}$ have shown that mechanical ventilation is an efficacious and well tolerated procedure for children who do not have underlying cardiac or pulmonary disease. This must be taken into consideration when defining for whom specific treatment might be cost effective.
We thank Drs D Nelson, G Delage, and J Guay for their valuable comments, Mrs M Vaillancourt for her assistance in statistical analysis, and Mrs S Tassé and Mrs L Chartier for their expert secretarial work.

\section{References}

1 Wohl MEB, Chernick V. Bronchiolitis. Am Rev Respir Dis 1978;118:759-81.

2 Phelan PD, Williams HE, Stocks JG, et al. Artificial ventilation in the management of respiratory insufficiency in acute bronchiolitis. Aust Paediatr J 1968;4:223-8.

${ }^{3}$ Hicks RA, Taylor JW, Jackson MA, Burry F, Olson LC. Epidemiology of a large respiratory syncytial virus (RSV) outbreak in Kansas City, Missouri. Pediatr Res 1986;20:228A.

4 Joly JB, Huault G, Amsili J, Lemerle J, Thieffry S. Place de l'intubation et de la ventilation artificielle dans le traitement des bronchoalvéolites graves du nourrisson. Arch Fr Pediatr 1967; 24:303-18.

5 Downes JJ, Wood DW, Striker TW, Haddad C. Acute respiratory failure in infants with bronchiolitis. Anesthesiology 1968;29: 426-34.

6 Outwater KM, Crone RK. Management of respiratory failure in infants with acute viral bronchiolitis. Am J Dis Child 1984;138: 1071-5.

${ }^{7}$ Frankel LR, Lewiston NJ, Smith DW, Stevenson DK. Clinical observations on mechanical ventilation for respiratory failure in bronchiolitis. Pediatr Pulmonol 1986;2:307-11.

${ }^{8}$ Floret D, Gabai E. La ventilation assistée des bronchiolites aiguës du nourrisson. Pediatrie 1986;41:189-95.

9 Dobson AJ. An introduction to statistical modeling. New York: Chapman and Hall, 1983:74-90.

10 Glezen WP, Pareder A, Allison JE, Taber LH, Frank AL. Risk of respiratory syncytial virus infection for infants from lowincome families in relationship to age, sex, ethnic group, and maternal antibody level. J Pediatr 1981;98:708-15.

1 Heycock JB, Noble TC. 1,230 cases of acute bronchiolitis in infancy. $\mathrm{Br}$ Med $J$ 1962;ii:879-81.

12 Committee on Infectious Diseases: American Academy of Pediatrics. Ribavirin therapy of respiratory syncytial virus. Pediatrics 1987;79:475-8.

13 Bruhn FW, Mokrohisky ST, McIntosh K. Apnea associated with respiratory syncytial virus infection in young infants. $J$ Pediatr 1977;90:382-6.

14 Church NR, Anas NG, Hall CB, Brooks JG. Respiratory syncytial virus related apnea in infants. Am J Dis Child 1984; 138:247-50.

15 Coates AL, Bergsteinsson H, Desmond K, Outerbridge EW, Beaudry PH. Long-term pulmonary sequelae of premature birth with and without idiopathic respiratory distress syndrome. J Pediatr 1977;90:611-6.

16 Bertrand JM, Riley SP, Popkin J, Coates AL. The long-term pulmonary sequelae of prematurity: the role of familial airway hyperreactivity and the respiratory distress syndrome. $N$ Engl J Med 1985;312:742-5.

17 Bernbaum J, Anolik R, Polin RA, et al. Development of the premature infant's host defense system and its relationship to routine immunizations. Clin Perinatol 1984;11:73-84.

18 Ballow M, Cates KL, Rowe JC, Goetz C, Desbonnet C. Development of the immune system in very low birth weight (less than $1500 \mathrm{~g}$ ) premature infants: concentrations of plasma immunoglobulins and patterns of infection. Pediatr Res 1986;20: 899-904.

19 Chantarojanabiri T, Nichols DG, Rogers MC. Lower airway disease: bronchiolitis and asthma. In: Rogers MC, ed. Textbook of pediatric intensive care. Baltimore: Williams and Wilkins, 1987:199-235.

20 Hall CB, Powell KR, Schnabel KC, Gala CL, Pincus PH. Risk of secondary bacterial infection in infants hospitalized with respiratory syncital viral infection. $J$ Pediatr 1988;113:266-71. 
21 Friis B, Andersen P, Brenoe E, et al. Antibiotic treatment of pneumonia and bronchiolitis. A prospective randomised study. Arch Dis Child 1984;59:1038-45.

22 Wald ER, Dashefsky B, Green M. In re ribavirin: a case of premature adjudication? J Pediatr 1988;112:154-9.

23 Roy CG. Ribavirin. Ambivalence about an antiviral agent. Am J Dis Child 1988;142:488-90.
Correspondence and requests for reprints to Dr M Gauthier, Department of Pediatrics, Hôpital Ste-Justine, 3175 Côte Ste-Catherine, Montréal, Québec, Canada, H3T 1 C5.

Accepted 28 April 1989 